Universidad de Lima

Facultad de Comunicación

Carrera de Comunicación

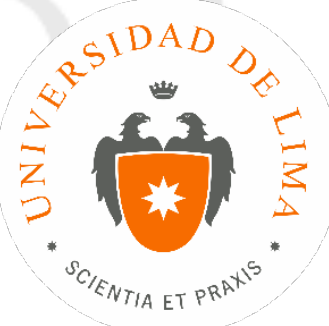

\title{
FASHION BLOGS: FACTORES DE ÉXITO E IMPORTANCIA COMO HERRAMIENTAS DE MARKETING
}

Tesis para optar el Título Profesional de Licenciado en Comunicación

\section{Andrea Silvana Rubio Cabanillas}

Código 20100996

Asesor

Peter Busse Cárdenas

Lima - Perú

Octubre de 2018 


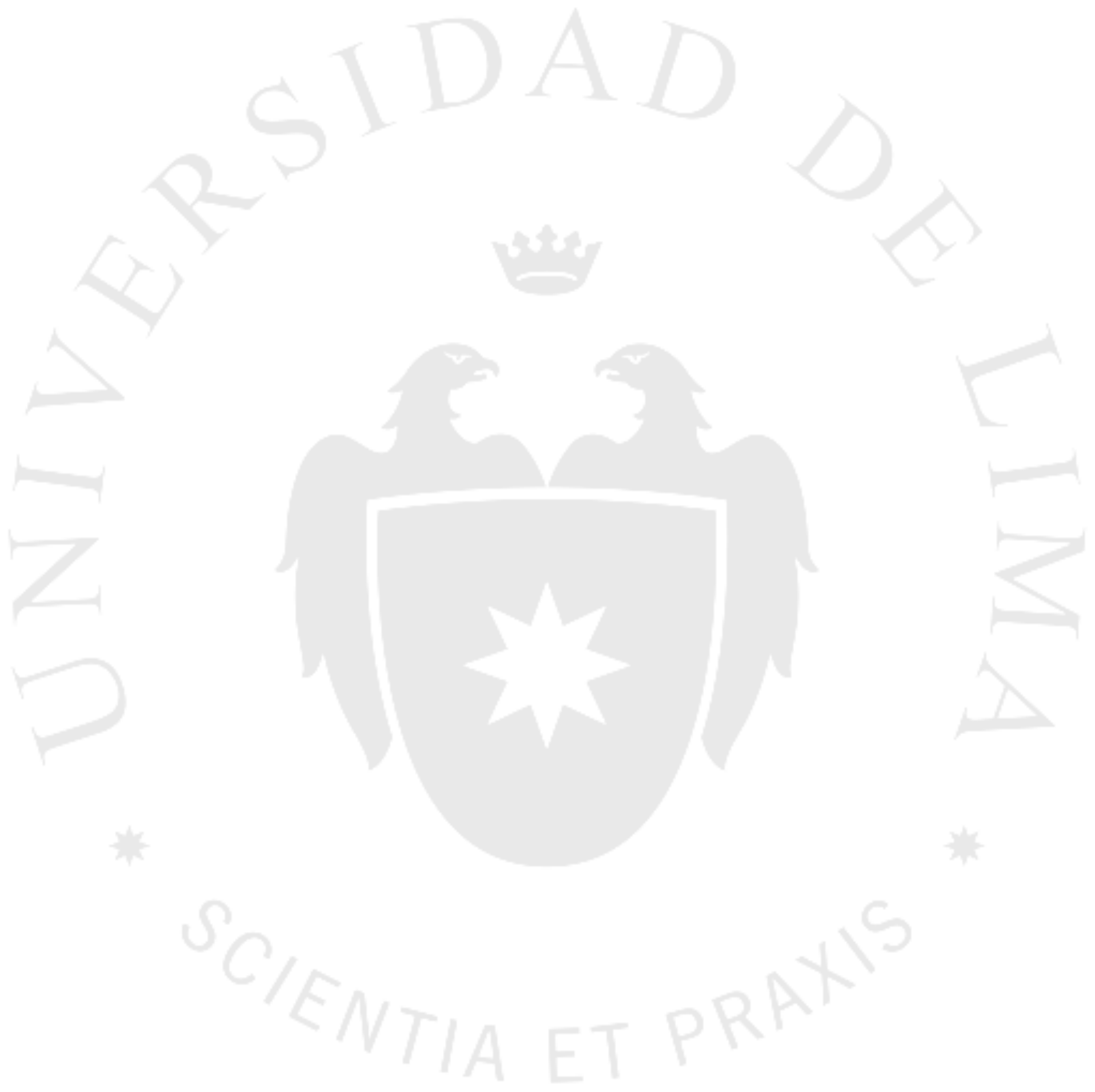


FASHION BLOGS: FACTORES DE ÉXITO E IMPORTANCIA COMO HERRAMIENTAS DE MARKETING 


\section{INTRODUCCIÓN}

\section{CAPÍTULO I: ANTECEDENTES Y MARCO CONTEXTUAL..1}

CAPÍTULO II: OBJETIVOS Y JUSTIFICACIÓN ..........................6

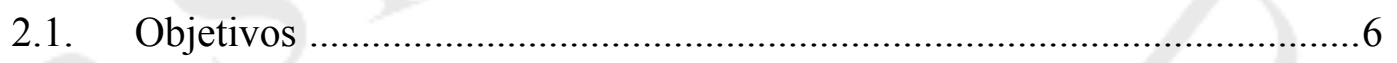

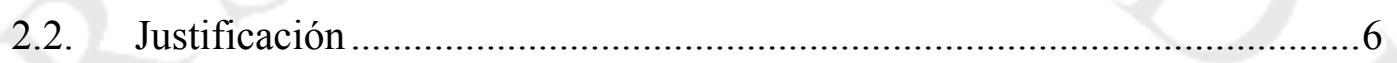

CAPÍTULO III: METODOLOGÍA.................................................8

CAPÍTULO IV: RESULTADOS ..................................................12

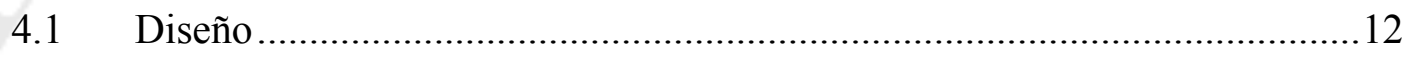

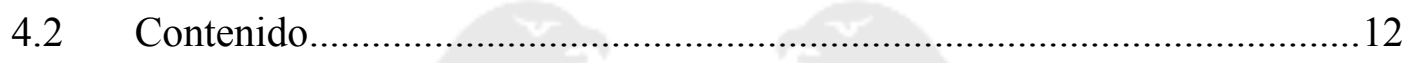

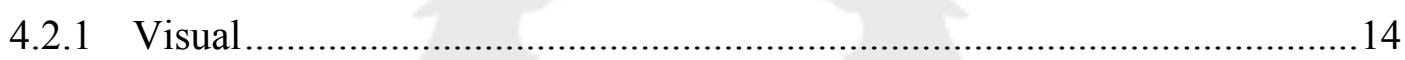

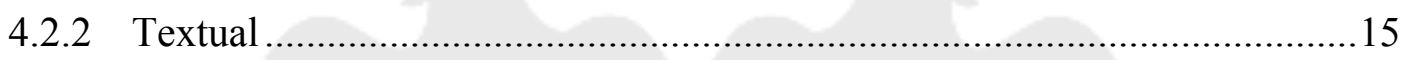

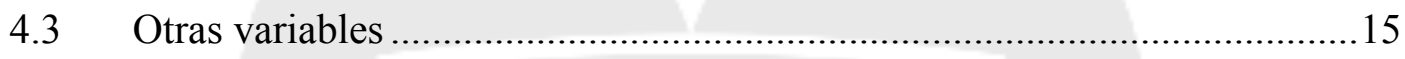

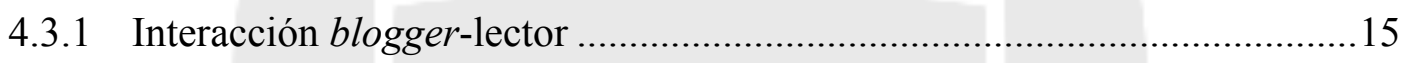

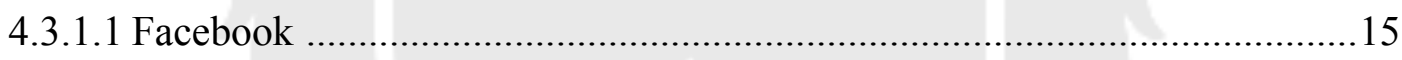

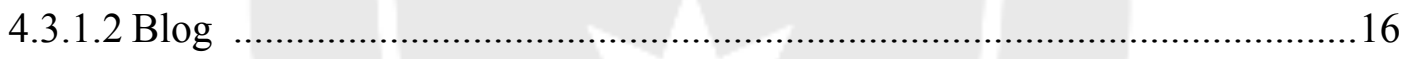

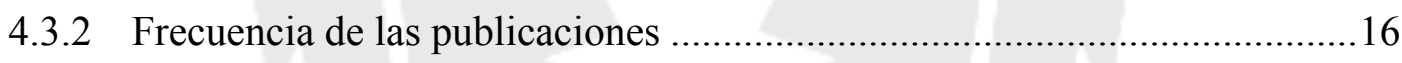

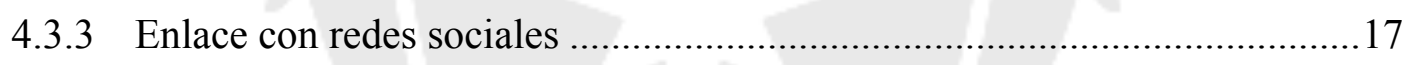

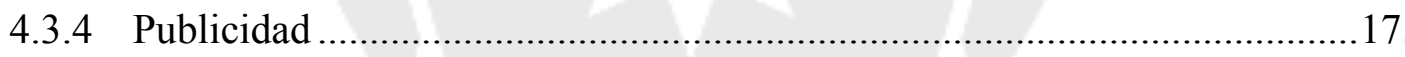

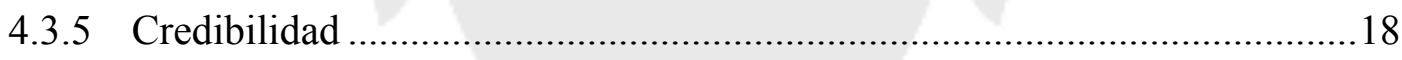

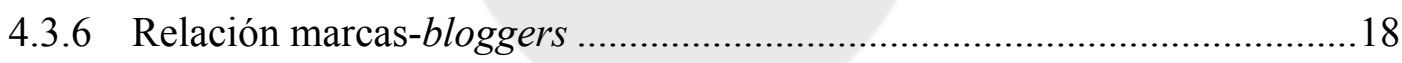

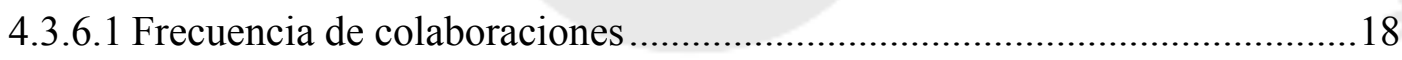

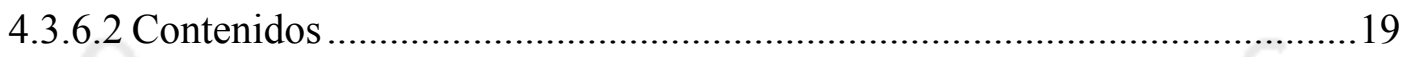

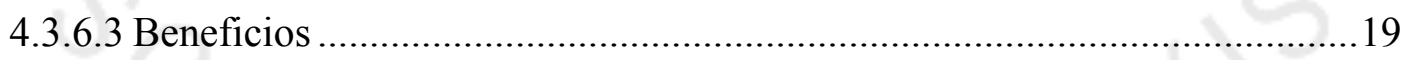

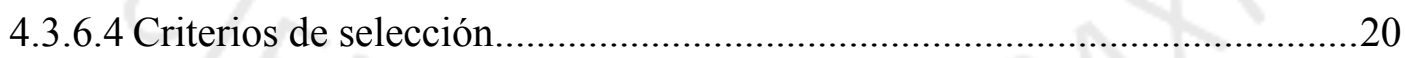

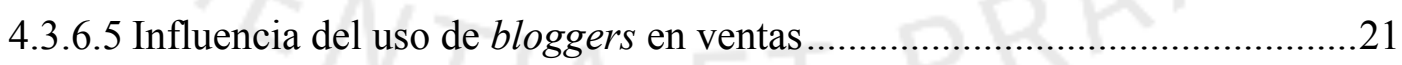

CAPÍTULO V: DISCUSIÓN...........................................................22

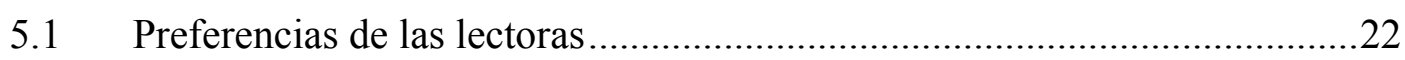

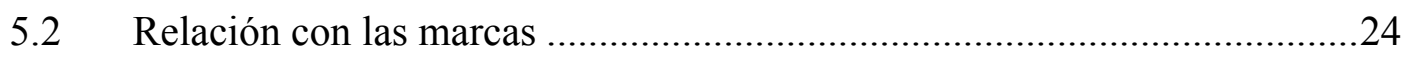

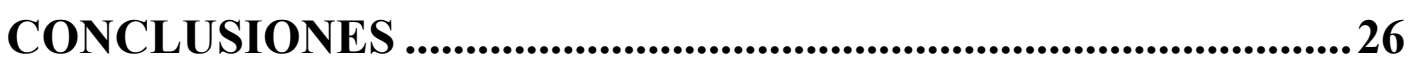


RECOMENDACIÓN ....................................................................28

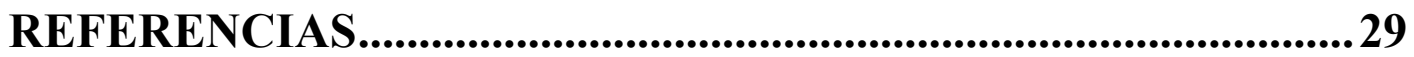

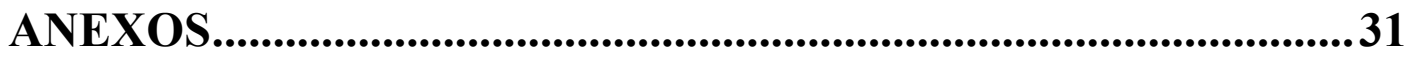




\section{ÍNDICE DE TABLAS}

Tabla 3.1. Blog “El Diario de Pink Chick".......................................

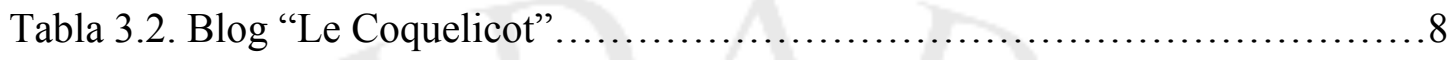

Tabla 3.3. Blog "Fashion in Da Hat"............................................

Tabla 3.4. Expertas en marketing entrevistadas.................................11

Tabla 4.1. Principales secciones que conforman los blogs..........................12

Tabla 4.2. Temas principales tocados en los posts.............................13

Tabla 4.3. Engagement Facebook............................................ 16

Tabla 4.4. Frecuencia de publicaciones en el blog..............................16 
ÍNDICE DE FIGURAS

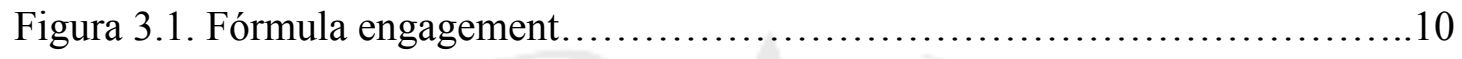




\section{ÍNDICE DE ANEXOS}

Anexo 1: Análisis de contenido.......................................... 32

Anexo 2: Focus group lectoras.............................................. 35

Anexo 3: Entrevistas a expertas de marketing ................................. 39 


\section{INTRODUCCIÓN}

Ante la saturación publicitaria a la que se enfrentan los consumidores hoy en día, las marcas han visto provechoso comunicar sus productos a través de fashion bloggers. Los fashion blogs se constituyen como espacios publicitarios donde los usuarios se informan sobre tendencias y toman decisiones sobre determinados productos. Estos se han vuelto más conocidos gracias a sus comunidades en constante crecimiento y sus continuas colaboraciones con marcas.

La presente investigación busca conocer los factores de éxito de los fashion blogs en términos de aceptación por parte de su público, para conocer las preferencias del consumidor y la relación de los bloggers con las marcas.

Para alcanzar este objetivo la investigación se dividió en cinco capítulos. El primer capítulo aborda los antecedentes y el marco conceptual; en él se mencionan investigaciones precedentes que giran en torno a los fashion blogs. Posteriormente, se presentan dos conceptos esenciales para comprender la relevancia de los mismos. En el segundo capítulo se detalla el objetivo principal, los objetivos específicos y la justificación de la investigación. El tercer capítulo describe la metodología empleada, compuesta por un análisis de contenido descriptivo, entrevistas a profundidad y focus group. El cuarto capítulo muestra de manera objetiva los resultados obtenidos y, finalmente, el quinto capítulo trata una discusión en torno a la investigación, tomando en cuenta los conceptos expuestos en el capítulo 1. Al final de la presente investigación, se presentan las conclusiones y recomendaciones. 


\section{CAPÍTULO I: ANTECEDENTES Y MARCO CONTEXTUAL}

Actualmente, contar con una estrategia de comunicación 2.0 es un aspecto indispensable para el reconocimiento y la supervivencia de una marca. Entre las características más importantes de las redes sociales, se encuentran la viralidad y la respuesta inmediata. Estos dos factores conllevan a que las redes sean un espacio ideal para generar engagement con el consumidor, awareness de la marca y aprovechar el feedback recibido de los usuarios (Pérez Curiel \& Clavijo Ferreira, 2017).

Al ser la industria de la moda uno de los sectores que más comentarios genera en las redes sociales, este tipo de interacción se vuelve fundamental. Esta última ventaja ha sido aprovechada por diversas marcas para participar en la conversación con sus consumidores e incrementar su imagen (Pérez Curiel \& Clavijo Ferreira, 2017).

Dentro de este esquema, los bloggers tienen un rol importante como influencers (Pérez Curiel \& Clavijo Ferreira, 2017). En la actualidad, las empresas buscan conectar de manera novedosa con sus públicos objetivos y los fashion blogs parecen ser el lugar ideal para crear lazos con los clientes. Según Gwyneth Moore, "la clave del éxito se encuentra en evitar enfoques de venta tradicionales que bombardean a los usuarios con información sobre las marcas” (Moore, 2013, p.131).

En este contexto, los fashion blogs permiten a las compañías llegar a su público a través de contenidos que los mismos usuarios buscan y comparten. Estos se han constituido como parte esencial del plan de marketing y de las estrategias de relaciones públicas de muchas de las empresas más importantes del mundo (Miller, 2010).

Hay distintos motivos por los cuales las marcas se interesan por los influencers. Según José Luis Villanueva, Head de Socialyse de Havas Group Perú, en las campañas publicitarias el uso de influenciadores se mide en base a dos puntos: "el número de seguidores que los bloggers tienen y el alcance que logran" (Moreno Espinoza, 2017, p.32). Estos dos factores resultan importantes porque un influencer, con gran repercusión, brinda la posibilidad de que el contenido se viralice (Moreno Espinoza, 2017). 
Las marcas cuentan con distintos criterios de selección para decidir con cual blogger o influenciador llevan a cabo una colaboración. Entre estos criterios se encuentran el posicionamiento del blog y del blogger, la credibilidad, reputación y profesionalidad con las que cuenta, su audiencia, su número de seguidores, la afinidad con la marca y, por último, el tráfico y las ventas que genera (Más Del Rey, 2015).

Son muchas las investigaciones que se han realizado en el campo de los fashion blogs en diferentes lugares del mundo, principalmente en Europa y en Estados Unidos. Estas abordan temas como el análisis de contenido de los blogs, las percepciones y actitudes del lector, la efectividad de la publicidad insertada en estos espacios, y la credibilidad y la influencia que tienen los bloggers sobre el lector.

Algunos ejemplos de estas investigaciones son: "Organic and amplified eWOM in consumer fashion blogs" de Marianne Kulmala, Nina Mesiranta y Pekka Tuominen (2013), "Following the Fashionable Friend: The Power of Social Media - Weighing the Publicity Effectiveness Of Blogs versus Online Magazines" de Jonas Colliander y Micael Dahlén (2011) y "Effective Fashion Blogs and Their Impact on the Current Fashion Industry” de Kristina Sedeke (2012).

En Perú, es notorio el auge que han tenido los fashion blogs en los últimos años (Ellos \& Ellas, 2013), por ello, se han llevado a cabo investigaciones que exploran este fenómeno. Entre ellas se encuentran la tesis de licenciatura de la Universidad de Lima realizada por Soledad Valenzuela en el 2013, la cual gira en torno a los fashion bloggers como influenciadores y a su propia experiencia como autora de "El diario de Pink Chick"; y, la tesis de licenciatura de la Pontificia Universidad Católica de Claudia Aco Sánchez, realizada en el 2014, titulada "Los blogs de moda como recurso publicitario para las marcas de moda peruanas". Igualmente, cabe mencionar una investigación más reciente, la tesis de licenciatura de la Universidad de Lima de María Fernanda Peña, realizada en el 2016, en la que se aborda el uso de influencers como parte de la estrategia de marketing de Saga Falabella.

La escasa información académica sobre el tema en nuestro país, el fuerte aumento de blogs y el evidente uso de bloggers para la promoción de marcas, son los principales motivos por los cuales se realiza esta investigación. Esta tiene como objetivo principal conocer los factores de éxito de los fashion blogs, en términos de aceptación por parte de su público, para comprender las preferencias del consumidor y 
la relación de los bloggers con las marcas.

Para la presente investigación, se tomaron en cuenta ciertos conceptos que ayudan a comprender distintas facetas de los fashion blogs. En primer lugar, la interacción parasocial (conocida por sus siglas en inglés como PSI de parasocial interaction) se entiende como la ilusión de una interacción cara a cara que puede ocurrir entre los personajes mediáticos (como presentadores, actores o celebridades) y su audiencia (Ballantine \& Martin, 2005). Los personajes mediáticos se dirigen a la audiencia directamente, simulando una conversación personal y privada, de manera que se entabla un vínculo de compromiso entre ambas partes (Ballantine \& Martin, 2005).

Entre los otros factores que generan esta cercana relación se encuentran, la revelación de diferentes aspectos de la vida privada del personaje mediático y las repetidas interacciones con la audiencia (Colliander \& Dahlén, 2011).

Kauppinen y Pavlova (2017) estudian el PSI en el contexto de los vlogs. Según los autores, una característica fuerte de estos es que, comúnmente, son construidos en base a los detalles personales compartidos por los vloggers, quienes están siempre dispuestos a la comunicación y a la interacción con su público. Esto genera fuertes relaciones entre ambas partes, pues los seguidores sienten que conocen más información personal del emisor (Kauppinen \& Pavlova, Mayo 2017).

Si bien estas dos últimas investigaciones no se desarrollaron en el marco de los fashion blogs, son totalmente aplicables a su entorno.

Colliander y Dahlén (2011) profundizan en el poder que tiene la interacción parasocial para formar vínculos estrechos entre bloggers y lectores. Ambos se basan en que los emisores muestran distintos aspectos de su vida privada e interactúan constantemente con sus comunidades, situación que se replica en el contexto de los $v \log s$.

Es importante resaltar que, si bien la noción inicial del PSI se basa en una comunicación unilateral, hoy, gracias a internet y las redes sociales, existe una comunicación bilateral. Los usuarios tienen la posibilidad de expresar su opinión, de “discutir" con los bloggers, marcas u otras entidades. Sin embargo, pese a que existe una interacción entre ambas partes, son los bloggers quienes, al contar con una influencia sobre sus seguidores, tienen el dominio de la relación. (Kauppinen \& Pavlova, Mayo 2017). 
En la actualidad, existen consumidores mejor informados y escépticos frente a la información que procede directamente de las empresas (Pérez Curiel \& Clavijo Ferreira, 2017), de modo que las opiniones de los demás resultan relevantes. Estas opiniones se conocen como el "boca a boca" (WOM por sus siglas en inglés: Word Of Mouth). Este tipo de interacción se entiende como una "comunicación cara a cara sobre productos o empresas entre personas que carecen de interés comercial" (López \& Sicilia, 2013, p.9).

Investigaciones anteriores han demostrado que el boca a boca es más persuasivo que la información comercial (López \& Sicilia, 2014). Por otro lado, debido al desarrollo tecnológico, aparece el $\boldsymbol{e W O M}$ (electronic Word Of Mouth), un "boca a boca" a través de internet y accessible a un sin número de personas, gracias a una permanencia indeterminada del mensaje (López \& Sicilia, 2013).

Esto da como resultado una comunicación bidireccional no simultánea, en donde cualquier persona puede actuar como emisor o receptor (López \& Sicilia, 2013). Asimismo, estudios anteriores han demostrado que el eWOM tiene una influencia en el comportamiento del consumidor y en las ventas (López \& Sicilia, 2014).

Dentro del eWOM se encuentra el Organic eWOM que, como su nombre deja entrever, se da de forma natural. Esto se puede apreciar cuando una persona quiere comunicar su experiencia positiva o negativa frente un producto, una marca o un servicio (Kulmala, Mesiranta, \& Tuominen, 2013). Esta acción surge naturalmente, con la intención de comunicar una experiencia, volviéndose una libre intervención de la empresa para promocionarse (Kulmala, Mesiranta, \& Tuominen, 2013).

En los fashion blogs, algunos de los temas orgánicos más comunes son el estilo personal, las experiencias con tendencias o con productos y la información relacionada a marcas. Por otro lado, el Amplified eWOM sucede cuando las marcas impulsan campañas a través de los blogs. Esto con el objetivo de lograr que se hable de ellas (Kulmala, Mesiranta, \& Tuominen, 2013). La importancia recae en que los temas impulsados bajo un interés comercial son presentados como temas orgánicos. Teniendo en consideración este último aspecto, para que las colaboraciones entre marcas y blogs sean efectivas y creíbles, los productos y contenidos deben ir con el estilo personal del blogger y con la atmósfera general del blog. De lo contario, las 
audiencias podrían reaccionar mal si notan que los productos anunciados no corresponden a la personalidad que estos espacios transmiten (Kulmala, Mesiranta, \& Tuominen, 2013).

El PSI y el $W O M$ son conceptos esenciales para poder entender mejor la credibilidad que poseen los bloggers y las relaciones que se entablan entre el lector y el escritor. Por un lado, gracias al PSI, los lectores esperan que los bloggers sean honestos en cuanto a su relación con las marcas y a los productos que prefieren, dada la preocupación por su público. Por otro lado, con el WOM, el receptor evalúa al emisor en base a la relación que tiene con el producto y a sus intenciones (Colliander \& Dahlén, 2011).

El vínculo que tiene el blogger con la empresa es un factor esencial para que el lector confíe en las recomendaciones dadas por el escritor. Según Chu y Kamal (2008), la credibilidad es una cualidad valorada en base a dos componentes: la confiabilidad y la experiencia. La confiabilidad es la creencia, por parte de la audiencia, de que se les provee información honesta; la experiencia, relaciona con la capacidad que tiene el blogger para proporcionar información auténtica acerca del tema (Chu \& Kamal, 2008).

En relación a la adquisición de productos, la credibilidad se vuelve importante cuando el consumidor no puede experimentarlos directamente y, en este caso, toma la palabra del escritor como garantía (Colliander \& Dahlén, 2011). Los bloggers comunican información y expresan su opinión acerca de los productos que usan, los cuales muchas veces no son probados directamente por el lector; por lo tanto, las opiniones que tenga el blogger resultan ser relevantes. 


\section{CAPÍTULO II: OBJETIVOS Y JUSTIFICACIÓN}

\subsection{Objetivos}

En base a los antecedentes revisados, la presente investigación tiene como objetivo principal conocer los factores de éxito de los fashion blogs en términos de aceptación por parte de su público, para comprender las preferencias del consumidor y la relación de los bloggers con las marcas.

En este mismo marco, el presente estudio propone responder a distintos objetivos específicos que resultan relevantes para la comprensión del tema:

- Identificar los principales contenidos utilizados en los blogs de moda peruanos.

- Identificar las preferencias de los consumidores en base a los contenidos, diseño y otras variables que resultan relevantes para los fashion blogs (características personales del blogger, interacción blogger-lector, frecuencia de las publicaciones, publicidad y credibilidad).

- Determinar la importancia de las redes sociales para los blogs en términos de tráfico e interacción.

- Conocer la importancia de trabajar en colaboración con fashion bloggers para una marca.

\subsection{Justificación}

Tal y como se mencionó en el primer capítulo, los fashion blogs se convirtieron en una alternativa interactiva y no tradicional para las empresas, con el objetivo de llegar a un grupo de usuarios (Moore, 2013, p.131). Por ello, tanto las compañías grandes e internacionales, como las más pequeñas, se interesan en utilizar este tipo de medios para posicionarse, aumentar su imagen de marca y promocionar sus productos.

"Fashion blogging" se ha convertido en todo un fenómeno con un gran impacto en la industria de la moda (Sedeke, 2012). El poder que tienen los fashion blogs como líderes de opinión, hace que se constituyan como actores influyentes durante el proceso de difusión de un producto (The Influence of Fashion Blogs on Consumers, 2012). 
La falta de información académica del tema y el evidente uso de fashion bloggers para las acciones de marketing y de comunicación de las marcas, son los principales motivos por los cuales se realizó esta investigación. En este contexto, para comprender el éxito que han tenido los fashion blogs, resulta relevante conocer las preferencias de los lectores y el punto de vista de las marcas que deciden trabajar con ellos. 


\section{CAPÍTULO III: METODOLOGÍA}

Para cumplir con los objetivos de la presente investigación, se realizó un análisis de contenido y se condujeron entrevistas y grupos focales.

Inicialmente, se realizó un análisis de contenido descriptivo de tres blogs que fueron seleccionados bajo los siguientes criterios:

- $\quad$ Más de cien mil likes en Facebook.

- Más de un año de antigüedad.

- Contar con publicidad de distintas marcas.

Dichos criterios condujeron a la selección y análisis de los tres blogs más visitados del Perú en 2015. A continuación, se presentan tres tablas con las características principales de los casos analizados durante la semana del 11 de mayo de 2015 al 17 de mayo del mismo año:

Tabla 3.1

Blog "El Diario de Pink Chick"

\begin{tabular}{|l|l|}
\hline \multicolumn{2}{|c|}{ EI Diario de Pink Chick } \\
\hline Autor & Soledad Valenzuela \\
\hline Fecha de creación & 2010 \\
\hline Número de fans en Facebook & 163,782 \\
\hline Publicidad/Marcas & Everlast, Cielo, Sedal, Free Tea \\
\hline Datos interesantes & $\begin{array}{l}\text { Uno de los blogs más leídos en el Perú } \\
\text { Soledad estudió comunicaciones }\end{array}$ \\
\hline
\end{tabular}

Fuente: elaboración propia

Tabla 3.2

Blog "Le Coquelicot"

\begin{tabular}{|l|l|}
\hline \multicolumn{2}{|l|}{ Le Coquelicot } \\
\hline Autor & Tana Rendón \\
\hline Fecha de creación & 2010 \\
\hline Número de fans en Facebook & 136,851 \\
\hline Publicidad/Marcas & $\begin{array}{l}\text { Bellissima, Warma, Saga Falabella, Sybilla, Bohem, } \\
\text { Impulse, Reebok }\end{array}$ \\
\hline
\end{tabular}


(continuación)

\begin{tabular}{|c|c|}
\hline Datos interesantes & $\begin{array}{ll} & \text { Blog que recibe más visitas en el Perú }(45 \mathrm{k})^{1} \\
\text { - } & \text { HOT Blogger de Saga Falabella e imagen de } \\
& \text { Sybilla } \\
\text { - } & \text { Tana es diseñadora de modas }\end{array}$ \\
\hline
\end{tabular}

Fuente: elaboración propia

Tabla 3.3

Blog "Fashion in Da Hat"

\begin{tabular}{|l|l|}
\hline \multicolumn{2}{|c|}{ Fashion in Da Hat } \\
\hline Autor & Alessandra Mazzini \\
\hline Fecha de creación & 2011 \\
\hline Número de fans en Facebook & 103,709 \\
\hline Publicidad/Marcas & Nike, Camote Soup, Shopbob, Doble Nudo \\
\hline Datos interesantes & $\begin{array}{l}\text { Alessandra es diseñadora de modas. } \\
\text { Dueña de la marca "Camote Soup" y de la } \\
\text { productora "Doble Nudo". }\end{array}$ \\
\hline
\end{tabular}

Fuente: elaboración propia

Para el análisis de contenido descriptivo, se establecieron una serie de categorías en base a las cuales se estudiaron los blogs: diseño, contenido y lo que se denominó “otras variables", en la cual se decidió agrupar temas relevantes.

A continuación, se detallarán los factores que se consideraron para el análisis de las categorías:

- Diseño: soporte de la página web, tipografía usada en el blog, colores y diagramación.

- Contenido: contenido visual (fotografías, imágenes y videos), contenido textual del post (análisis del estilo de redacción). En base a estos se buscó determinar las principales secciones que conforman un blog, además de los temas más importantes expuestos en un post.

- Otras variables: características de la blogger (estilo personal y experiencia), interacción blogger-lector, frecuencia de las publicaciones, enlace con redes sociales, publicidad y credibilidad.

\footnotetext{
${ }^{1}$ Similarweb.com
} 
Para conocer y comprender cuál era la interacción entre las bloggers y las lectoras, se contabilizaron los comentarios de los blogs y de los perfiles de Facebook de cada caso. Asimismo, el engagement sirvió para medir el vínculo y la interacción de las lectoras con el fanpage de Facebook de cada blog. Es decir, el nivel de compromiso existente entre ambas partes. Cuando la participación de los usuarios es mayor (cuando hay más likes, más comentarios o posts compartidos), el compromiso con la marca también lo es (Puro Marketing, 2014). En base a esto, se aplicó la siguiente fórmula para cada uno de los casos seleccionados:

Figura 3.1

Fórmula engagement.

$$
\text { Engagement }=\frac{\text { Me gustas }+ \text { Comentarios }+ \text { Compartidos }}{\text { Número de seguidores }}
$$

Fuente: Ávila, Clara, 2014

El análisis de los blogs, junto con las entrevistas a las bloggers, permitió determinar si existía un calendario editorial para la producción de contenidos.

Se realizaron tres entrevistas a las bloggers, propietarias de los casos seleccionados, para indagar acerca de sus procesos de producción de contenidos. Las preguntas giraron en torno a las categorías “contenido" y "otras variables", establecidas anteriormente.

Por otra parte, se realizaron dos focus group a consumidoras frecuentes de blogs de moda entre los 20 y 25 años, de los NSE A y B. Estos giraron en torno a las categorías "contenido" y "otras variables" para poder identificar las preferencias de las lectoras. El objetivo de estos fue poder validar la información y, para complementarla, se realizaron dos entrevistas a profundidad a lectoras frecuentes de estos espacios.

Por último, con el objetivo de conocer la importancia de los fashion blogs como herramientas de marketing para las empresas, se realizaron cinco entrevistas estructuradas a expertas y responsables en marketing que trabajan en la categoría de belleza o retail.

\footnotetext{
2 Fórmula encontrada en el blog Claraavila.com, Clara Ávila es Ingeniera Técnica de Telecomunicaciones de la Universidad Carlos III de Madrid.
} 
En la siguiente tabla, se detallan sus nombres, puestos y las empresas para las cuales trabajan.

Tabla 3.4

Expertas en marketing entrevistadas.

\begin{tabular}{|l|l|l|}
\hline \multicolumn{1}{|c|}{ Nombre } & \multicolumn{1}{c|}{ Puesto } & \multicolumn{1}{c|}{ Empresa } \\
\hline Alejandra Aldave & $\begin{array}{l}\text { Jefa de Producto InOutlet Premium Lurín e InOutlet } \\
\text { Faucett }\end{array}$ & Parque Arauco \\
\hline Eliana Obregón & Jefa de Producto Larcomar & Parque Arauco \\
\hline Evelyn Uribe & Jefa de Marketing C.C. La Rambla. & Urbanova \\
\hline Andrea Cruz & Jefa de Marketing Mac Cosmetics & $\begin{array}{l}\text { The Estée Lauder } \\
\text { Companies }\end{array}$ \\
\hline Valeria Ugaz & Coordinadora de Marketing L'Oréal Professionnel. & L'Oréal Perú \\
\hline
\end{tabular}

Fuente: elaboración propia 


\section{CAPÍTULO IV: RESULTADOS}

En el presente capítulo se muestran los resultados obtenidos gracias al análisis de contenido descriptivo de los tres blogs seleccionados, las entrevistas y los focus group. Estos resultados fueron clasificados bajo las mismas métricas que la metodología: diseño, contenido y "otras variables".

\subsection{Diseño}

Los tres blogs seleccionados cuentan con un dominio personal. Esto, según las lectoras, hace que el blog tenga una imagen más profesional. Todas resaltaron la importancia de la legibilidad, lo cual va ligado a que, el uso de colores y tipografías, no molesten la presentación del contenido principal. Asimismo, prefieren los diseños minimalistas porque brindan mayor notoriedad a los contenidos.

\subsection{Contenido}

En base al análisis de blogs realizado, entre las principales secciones que conforman estos espacios se encuentran: "Home", "Looks", "About", "Contacto", "Viajes", "Belleza", "Nuevas adquisiciones" o "Compras" y "Noticias".

A continuación, se muestra en el siguiente cuadro una breve descripción de cada sección:

Tabla 4.1

Principales secciones que conforman los blogs

\begin{tabular}{|l|l|}
\hline \multicolumn{1}{|c|}{ Sección } & \multicolumn{1}{c|}{ Descripción } \\
\hline Home & Posts que sube la blogger, ordenados cronológicamente en reversa. \\
\hline Looks & Outfits posts de las bloggers. \\
\hline About & Descripción profesional y personal de la blogger. \\
\hline Contacto & Espacio para contactar a la blogger. \\
\hline Viajes & Sección en donde aparecen, únicamente, los viajes de las bloggers. \\
\hline Belleza & $\begin{array}{l}\text { 2 de los } 3 \text { blogs, cuentan con una sección en la que escriben sobre } \\
\text { distintos consejos de belleza, peinados, entre otros. }\end{array}$ \\
\hline
\end{tabular}

(continúa) 
(continuación)

\begin{tabular}{|l|l|}
\hline $\begin{array}{l}\text { Nuevas } \\
\text { adquisiciones/Compras }\end{array}$ & Las bloggers comparten sus nuevas adquisiciones. \\
\hline Noticias & Novedades en moda. \\
\hline
\end{tabular}

Fuente: elaboración propia

Como se puede observar en la siguiente tabla, "Temas principales tocados en los posts", la mayoría de las publicaciones durante la semana de análisis fueron outfit posts ( 5 de 15, en total, en los 3 blogs), de los cuales 1 se trató de un auspicio. En segundo lugar están los posts de belleza (4 de 15), en estos 3 eran auspicios.

Las lectoras señalaron preferir los outfit posts dado que los validan como fuentes de "inspiración” y resultan una ventana de información de marcas.

Tabla 4.2

Temas principales tocados en los posts

\begin{tabular}{|c|c|c|c|}
\hline Blog & Título del post & Tema del post & $\begin{array}{r}\text { Referencia a } \\
\text { vida persona }\end{array}$ \\
\hline \multirow{3}{*}{ Fashion in da Hat } & "Geometric Colors" & Outfit post & Sí \\
\hline & "De nuestra tierra" & Style hunt & No \\
\hline & "Y así decidí empezar" & Marcas & Sí \\
\hline \multirow{6}{*}{$\begin{array}{l}\text { El Diario de Pink } \\
\text { Chick }\end{array}$} & $\begin{array}{l}\text { "¿Cómo me pongo una falda } \\
\text { estampada?” }\end{array}$ & Outfit post & No \\
\hline & $\begin{array}{l}\text { "18 cosas que todos quieren saber (o } \\
\text { imaginan) de las fashion bloggers" }\end{array}$ & Otros - Listículos & Sí \\
\hline & $\begin{array}{l}\text { "Un peinado de moda fácil y rápido } \\
\text { de copiar en casa" }\end{array}$ & Belleza & No \\
\hline & "De la universidad al trabajo" & Outfit post & Sí \\
\hline & “¿Quieres estar en la lista?” & Concurso & Sí \\
\hline & $\begin{array}{l}\text { "¿Cómo hacer ondas naturales para } \\
\text { el pelo?" }\end{array}$ & Belleza - Auspicio & No \\
\hline \multirow{5}{*}{ Le Coquelicot } & $\begin{array}{l}\text { "5 pasos para secar el cabello en } \\
\text { casa" }\end{array}$ & Belleza - Auspicio & Sí \\
\hline & "5 zapatos b\&w @butrich" & Marcas & No \\
\hline & "Básicos y accesorios" & Outfit - Auspicio & 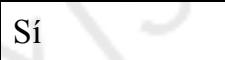 \\
\hline & “¡iHola NYC!!” & Viajes & Sí \\
\hline & $\begin{array}{l}\text { "Probando cepillo térmico y plancha } \\
\text { Bellissima" }\end{array}$ & Belleza - auspicio & No \\
\hline & $\begin{array}{l}\text { "¿Cómo combinar chaquetas de } \\
\text { color pastel?" }\end{array}$ & Outfit post & Sí \\
\hline
\end{tabular}

Fuente: elaboración propia 
Pese a que todas las bloggers entrevistadas señalaron realizar un cronograma de publicaciones, aseguraron que los temas a tratar se ven fuertemente influenciados por factores coyunturales, como colaboraciones con marcas, clima o aperturas de tiendas.

Cabe resaltar que de los 15 posts analizados en total, 9 mencionan aspectos de la vida privada y cotidiana de la autora. Con respecto a esto, aunque exista un "grupo de lectoras" que demuestran interés por la vida personal de la blogger, la mayoría no mostró inclinación por esos temas. No obstante, ambos grupos concuerdan en que esos aspectos dotan de personalidad al blog y hacen que se diferencie frente a los demás.

En las entrevistas, las bloggers afirmaron establecer límites en cuanto a lo que comunican sobre su vida privada. Temas como negatividad o "exponer" a sus familiares están fuera de discusión. De igual manera, concuerdan que estos aspectos generan una vínculo con el lector.

\subsubsection{Visual}

En los tres blogs analizados es notoria la calidad fotográfica, tanto en los aspectos técnicos como en los conceptuales.

Las bloggers aseguraron tomar medidas para mantener ciertos estándares de calidad. Por parte de las lectoras, estas destacaron la importancia de las fotografías al asociarlo con el interés y profesionalismo de la blogger. Además, este aspecto constituye parte de los elementos determinantes para que las lectoras sigan o no un fashion blog.

Con respecto a las imágenes durante el periodo de análisis, solo un blog publicó un post con imágenes obtenidas de internet. En los focus groups, las lectoras reconocieron que las bloggers utilizan constantemente imágenes referenciales que, pese a ser obtenidas de internet, es importante que tengan una buena calidad.

En relación a los videos, ninguna de las bloggers subió uno nuevo durante el periodo de análisis. No obstante, cada blog cuenta con un canal en Youtube en el que suben tutoriales, comparten sus experiencias y dan consejos relacionados a moda o estilo de vida. Con respecto a esto, la mayoría de lectoras dijo preferir los videos cortos y los tutoriales. Además, señalaron que estos les permiten percibir cómo es realmente la blogger al poder oír su voz, ver su forma de hablar y otros aspectos que humanizan su imagen. 


\subsubsection{Textual}

En cuanto al estilo de redacción, cada blogger cuenta con un tono de comunicación que se ajusta a su personalidad. Pese a que todas escriben en primera persona, se dirigen a las lectoras en tercera. Además, utilizan un lenguaje sencillo, juvenil y cordial (incluso afectivo, en algunos casos).

Las lectoras señalan que es importante que el lenguaje sea fácil de entender. Esta razón se vuelve primordial para la lectura de los fashion blogs, porque pueden conocer más de moda sin necesidad de adentrarse en un lenguaje técnico y complicado. Un grupo de lectoras señaló sentir que las bloggers se dirigían a ellas como si "fueran amigas". Pese a ello, la mayoría aseguró ignorar el contenido textual y solo ver las fotografías, ya que los grandes bloques de texto les generan pesadez.

\subsection{Otras variables}

En cuanto al estilo personal -en el sentido de cómo se viste la blogger-, todas las lectoras expresaron que este era un motivo esencial por el cual seguían un blog. Por último, en cuanto a la experiencia, la mayoría de lectoras señaló confiar en las recomendaciones de las bloggers al ser personas más interesadas en moda y, por lo tanto, mejor informadas.

\subsubsection{Interacción blogger-lector}

\subsubsection{Facebook}

Gracias a la fórmula de engagement, se pudo determinar que "Le Coquelicot" es el blog con mayor interacción en Facebook (3.34\%), seguido de "Fashion In Da Hat" y "El Diario de Pink Chick", con igual porcentaje de interacción (2.16\%).

Estos resultados coinciden con que "Le Coquelicot" posee la mayor cantidad de comentarios durante el periodo de análisis (52 comentarios); y que Tana Rendón es la blogger que más responde (29 comentarios respondidos). Seguido se encuentra "Fashion In Da Hat", con un total de 36 comentarios, de los cuales 3 fueron respondidos. Finalmente, "El Diario de Pink Chick" contó con 8 comentarios en total, de los cuales se respondió 1 . 
En la siguiente tabla se muestran los datos analizados para obtener el engagement de cada blog.

Tabla 4.3

Engagement Facebook

\begin{tabular}{|l|l|l|l|}
\hline \multicolumn{1}{|c|}{ Blog } & Núm. fans & \multicolumn{1}{c|}{$\begin{array}{c}\text { Núm. } \\
\text { likes/comments/shares }\end{array}$} & \multicolumn{1}{c|}{ Engagement } \\
\hline El Diario de Pink Chick & 163782 & 3544 & $2.16 \%$ \\
\hline Le Coquelicot & 136851 & 4567 & $3.34 \%$ \\
\hline Fashion In Da Hat & 103709 & 2251 & $2.17 \%$ \\
\hline
\end{tabular}

Fuente: elaboración propia

\subsubsection{Blog}

En cuanto a los comentarios en el blog, "Le Coquelicot" fue el que tuvo mayor cantidad de comentarios acumulados (57 comentarios), seguido de "Fashion In Da Hat" (24 comentarios) y, por último, "El Diario de Pink Chick" (8 comentarios).

\subsubsection{Frecuencia de las publicaciones}

Tal y como se observa en la tabla "Frecuencia de publicaciones en el blog", la bitácora con mayor posts en la semana fue "El Diario de Pink Chick", seguido de "Le Coquelicot" y, por último, "Fashion In Da Hat".

Tabla 4.4

Frecuencia de publicaciones en el blog

\begin{tabular}{|l|l|l|}
\hline \multicolumn{1}{|c|}{ Blog } & \multicolumn{1}{|c|}{$\begin{array}{c}\text { Núm. de publicaciones } \\
\text { semanales }\end{array}$} & \multicolumn{1}{c|}{ Frecuencia } \\
\hline Fashion In Da Hat & 3 & $\begin{array}{l}\text { Martes, miércoles y domingo } \\
\text { domingo }\end{array}$ \\
\hline El Diario de Pink Chick & 6 & $\begin{array}{l}\text { Lunes(2), martes (2), jueves, } \\
\text { domingo }\end{array}$ \\
\hline Le Coquelicot & 6 & \\
\hline
\end{tabular}

Fuente: elaboración propia 
En los focus group, la mayoría de lectoras señaló preferir que no se publique todos los días, pero que sí se tenga un ritmo para que no se pierda el interés. Con respecto a las entrevistas, 2 de las 3 bloggers señalaron postear todos los días; a diferencia de Tana, quien busca hacer menos posts (inter-diarios), pero hacerlos más relevantes.

\subsubsection{Enlace con redes sociales}

De los 16 posts analizados, 15 fueron compartidos en Facebook. Las tres bloggers aseguraron publicar todos los días en las redes sociales, debido a que consideran que por este medio mantienen mayor interacción con las lectoras. Por otro lado, estas últimas concuerdan que es importante que las bloggers publiquen fotografías en las redes sociales todos los días, para mantener vivo el contacto.

Estas publicaciones diarias no llegan a saturarlas, debido a que son consideradas contenido "fácil de digerir". La mayoría de lectoras expresa que las redes sociales forman parte de los principales canales por los cuales acceden al blog y se enteran de los últimos posts. Por último, existe una preferencia a las publicaciones en Instagram frente a Facebook, ya que el segundo es considerado un espacio más personal.

\subsubsection{Publicidad}

Se determinaron tres tipos de publicidad en los blogs. El primero, publicidad en forma de banners. Estos no necesariamente correspondían a marcas de moda. Sin embargo, sí guardaban relación con la imagen de las bloggers. Con respecto a esto, las bloggers mencionaron que las marcas con las que trabajan no necesariamente deben ir con su estilo, pero sí deben estar en línea con los valores del blog.

La segunda forma de publicidad se da a través de menciones. Esto va de la mano con el uso de enlaces. Las bloggers, al mencionar una marca, vinculan el website o el fanpage de la misma.

El tercer tipo de publicidad, posts dedicados a una marca. Durante el periodo de análisis, 5 de los 15 post fueron auspiciados. Estos presentan los beneficios de los productos, al igual que información complementaria como tiendas, websites o perfiles en redes sociales. La forma en la que son presentados se asemeja al trato de 
publicaciones orgánicas, ya que los temas son presentados a manera de consejos o tutoriales.

Por la parte de las lectoras, todas expresaron ser conscientes de la publicidad en los blogs y que esta no les molesta, siempre y cuando cumpla con una serie de requisitos: En primer lugar, las marcas deben ir con el estilo y personalidad de la blogger. Esto garantiza que sus recomendaciones sean honestas porque prefieren el producto que están aconsejando. El segundo requisito, que la publicidad no sea demasiado obvia. La mayoría de lectoras prefieren las menciones más naturales. Por último, aseguran que no les molesta la publicidad a manera de banners, mientras estos tengan un espacio determinado en el blog y no interrumpan la lectura del contenido principal (como en el caso de los pop ups).

\subsubsection{Credibilidad}

En base a lo conversado en los focus group, se pudo determinar tres factores por los cuales las lectoras confían en los fashion blogs.

En primer lugar, la calidad del contenido genera que las lectoras perciban como profesionales a las bloggers. Por otro lado, las lectoras confían en las recomendaciones de las bloggers porque las consideran "expertas" o personas con mucho más conocimiento del tema, gracias a su interés por la moda o su profesión (muchas de ellas han realizado estudiados en moda). Por último, la credibilidad se refuerza mediante la presentación de resultados de un determinado producto.

\subsubsection{Relación marcas-bloggers}

Todas las expertas entrevistadas afirmaron haber trabajado anteriormente con bloggers para distintas campañas de marketing.

\subsubsection{Frecuencia de colaboraciones}

La frecuencia de las colaboraciones varía dependiendo de cada marca, su estrategia digital y del presupuesto destinado a la contratación de influencers. Por ejemplo, debido a que tienen un presupuesto más grande para estos propósitos y que este tipo de 
comunicación constituye la forma principal de conectar con su público, la marca Mac utiliza esta estrategia de manera frecuente (casi todas las semanas). En cambio, InOutlet realiza 3 o 4 veces al año campañas grandes que buscan tener un mayor impacto y alcance.

\subsubsection{Contenidos}

La mayoría de expertas entrevistadas aseguró que la generación de contenidos se hace en conjunto con la blogger. Al inicio de este proceso, la empresa brinda información sobre la marca y explica la campaña o acción a la blogger, detallando cuáles son los objetivos de comunicación. Posteriormente, la blogger presenta a la marca las métricas y resultados de su blog y de sus redes sociales.

Cabe resaltar que las bloggers pueden proponer distintas recomendaciones o formas de trabajo a las empresas, al tener un mayor conocimiento de su público y saber qué es lo que funciona mejor. De esta manera, ambas partes determinan en conjunto qué tipos de contenidos se van a publicar y en qué plataformas.

En algunos casos, como en el de Mac, es posible establecer un calendario de contenidos para evitar que las publicaciones se crucen con comunicaciones de otra marca que la blogger pueda tener pendiente. Terminada la campaña o acción, la blogger entrega a la empresa un reporte con los resultados generados por su parte en términos de alcance en redes sociales, número de comentarios, compartidos, engagement, entre otros datos.

\subsubsection{Beneficios}

Los principales beneficios mencionados por las entrevistadas fueron tres:

- El alcance de las bloggers o influencers: las bloggers cuentan con una alta cantidad de seguidores, lo que permite a las marcas llegar a un gran número personas a un precio bastante cómodo, comparado con la publicidad en medios masivos. De la misma manera, logran conocer con precisión a quiénes están llegando.

- La credibilidad: las bloggers son consideradas por sus seguidoras como personas "comunes y corrientes" que hacen recomendaciones sobre 
servicios y productos, por lo que se sienten identificadas con ellas. Muchos de los consumidores creen en sus recomendaciones al pensar que no están recibiendo algún tipo de remuneración por parte de una marca.

- La creación de cercanía: Los consumidores se sienten identificados con ellas. Las siguen en su día a día a través de redes sociales y sienten que son personas cercanas: viven en el mismo país o ciudad, frecuentan los mismos lugares, pueden comprar en las mismas tiendas, entre otros aspectos que generan empatía con las lectoras.

\subsubsection{Criterios de selección}

Los principales criterios de selección que nombraron las entrevistadas para trabajar con una blogger son:

- La audiencia de la blogger: es importante que esta coincida con el público al que quiere llegar la empresa. Por ejemplo, para la campaña "El Shopping Bus" de InOutlet se contrató a Vanessa Rodríguez, una madre de familia que tiene un público de 25 a 40 años, el cual concuerda con el target al que la marca quería llegar (personas que tienen la capacidad económica para transportarse hasta el outlet en auto, pagar peajes y realizar compras).

- El número de seguidores: es importante el alcance que tiene la blogger para llegar a un amplio número de personas.

- El engagement: no solo es importante que tenga bastantes seguidores, sino que tenga interacción con ellos. Según una de las expertas, no resulta beneficioso contratar a una blogger que tiene un gran número de fans pero que no tiene un buen engagement. Este último es un indicador de que la blogger tiene una relación más activa y fuerte con sus seguidoras.

- El posicionamiento de la blogger: si bien el alcance es un punto fundamental para la elección de la blogger, el posicionamiento de la misma constituye un factor más relevante. Tiene que ser coherente con el de la marca.

- La afinidad con la marca: la blogger debe tener afinidad con la marca y su imagen debe ser congruente con el mensaje que la empresa brinda. Esto asegura que la campaña sea creíble, atractiva y relevante para el público. 
- Con qué otras marcas se relacionan: para una empresa es importante con qué otras marcas se relaciona la blogger. Estas marcas no deben romper con el discurso de la empresa ni tener un valor considerado inferior. Por ejemplo, en el caso de Mac Cosmetics, la Jefa de Marketing asegura que si una influencer trabaja constantemente con marcas de consumo masivo, no estaría proyectando la imagen que Mac desea y por ende, como influenciadora, no sería conveniente para la empresa.

- El background de la blogger: la personalidad, los estudios, las experiencias personales y profesionales toman importancia cuando una marca quiere trabajar con una blogger. Por ejemplo, en el caso de La Rambla, se seleccionó a Talía Echecopar como influencer para comunicar distintas acciones del mall, debido a que cuenta con una maestría en moda que aporta valor a su trabajo.

\subsubsection{Influencia del uso de bloggers en ventas}

Todas las entrevistadas acordaron que el uso de bloggers sí influye en las ventas cuando las acciones que se realizan con ellas son tácticas. Por ejemplo, si se trata de un lanzamiento de producto o de una campaña de "sale", sí es posible ver una influencia a corto plazo en las ventas. En cambio, si es una campaña de branding, se medirá mejor a largo plazo, ya que su objetivo está más orientado a la construcción de marca.

Igualmente, todas las entrevistadas acordaron que el uso de bloggers influye en el comportamiento del consumidor, al verla "como una amiga" que da recomendaciones. 


\section{CAPÍTULO V: DISCUSIÓN}

En este quinto capítulo se hace una reflexión acerca de los resultados mostrados en el episodio anterior. Estos se interpretan en base a los conceptos vistos al inicio de la investigación, con el fin de poder entender las distintas percepciones y preferencias de los lectores, y los beneficios para las marcas al trabajar con un fashion blogger.

\subsection{Preferencias de las lectoras}

Gracias a la investigación realizada, fue posible determinar las distintas preferencias de las lectoras en cuanto a los fashion blogs peruanos.

En primer lugar, el diseño es el reflejo de la personalidad y del estilo de la blogger. La calidad del mismo influye en las percepciones que las lectoras desarrollan del blog. Por ello, resulta importante crear un diseño que permita ver los contenidos sin problemas y que sea atractivo. Este se constituye como una carta de presentación ante el público.

En cuanto al contenido, los outfit posts son los tipos de publicaciones preferidos por las lectoras y más utilizados por las bloggers. Esta preferencia se basa en el hecho de que son considerados una fuente de información de moda. Estos resultados nos permiten comprobar que, actualmente, los fashion blogs constituyen espacios publicitarios importantes, ya que son las lectoras quienes los buscan para informarse sobre productos y marcas. Por ello se puede decir que, si una marca quiere aumentar su notoriedad o posicionarse en el mercado, hacer una alianza con una blogger es una manera no intrusiva de darse a conocer.

Por otra parte, en relación a la forma del contenido, el estilo de redacción de la blogger es uno de los motivos principales por el cual se crea una relación de compromiso con su audiencia. Las bloggers, al escribir de manera personal y dirigirse directamente a las lectoras, generan que estas últimas sientan que se les está hablando con cercanía -tal y como sucedía con la interacción parasocial y los medios masivos (Ballantine \& Martin, 2005). 
Gran parte de las participantes mencionaron sentir que las bloggers las trataban como si fueran sus amigas. Un aspecto que refuerza este vínculo es el uso constante de las redes sociales por parte de ellas. Estas comparten videos de su vida cotidiana a través de los stories, disponibles en Instagram, en los cuales se dirigen a sus seguidoras de manera cercana.

En relación al contenido visual, las fotografías, al ser la primera impresión que las lectoras tienen de la blogger se constituyen como los elementos más importantes. Son el enganche para que estas se animen a entrar a un blog. Además, se debe considerar que la mayoría dijo ignorar el contenido textual cuando visita un fashion blog y solo enfocarse en las fotografías. Por este motivo, se considera determinante que un fashion blog mantenga ciertos estándares de calidad en las fotos. Caso contrario y, dada la gran oferta que hay actualmente, lo más probable es que las lectoras abandonen la página y busquen otro blog.

En la actualidad, las bloggers han comenzado a realizar más videos, y es a través de ellos que las lectoras las perciben de una manera más real, lo cual humaniza su imagen. Por ello, se predice que la elaboración de videos irá en aumento, lo cual permitirá a las bloggers tener un mayor alcance y mantener una conexión con su comunidad.

La mayoría de lectoras son conscientes de la publicidad en los fashion blogs. No obstante, esto no les molesta siempre y cuando vaya con el estilo de la blogger, no sea demasiado obvia y no interrumpa la lectura del contenido principal. Las marcas y las bloggers deben ser cuidadosas en la forma en que introducen publicidad. Si no cumplen con las condiciones señaladas, podrían generar molestia o ser percibidas como "vendidas" (es decir, que sus intenciones no son realmente ayudar o expresar sus gustos, sino únicamente ganar dinero).

Gracias al análisis, se pudo comprobar que las bloggers suelen presentar la publicidad como contenido orgánico. Es decir, al mencionar los beneficios de un producto, lo hacen relacionándolo con su interés personal y sus experiencias.

La credibilidad se constituye como un factor esencial para generar arraigo con las lectoras. Si estas perciben que las intenciones de las bloggers no son sinceras, se genera rechazo. Es importante para las seguidoras sentir que están siendo sinceras con ellas, en cuanto a las relaciones que tienen las bloggers con las marcas. 
Ya sea porque han estudiado algo relacionado a moda o porque, al ser apasionadas de esta industria, manejan mayor información, otro factor que influye en la credibilidad es su experiencia. Finalmente, para que las bloggers mantengan la credibilidad que han forjado, es importante mostrar los resultados del uso de un producto. Esto genera una actitud positiva en las lectoras, quienes evidencian buenas intenciones e interés por recomendar algo que ha sido probado, anteriormente, por ellas.

Con respecto a la interacción, "Le Coquelicot" es el blog que presenta una mayor tasa y Tana Rendón, la blogger de este, es quien más responde comentarios. En base a esto, se puede decir que un mayor porcentaje de respuesta por parte de las bloggers genera una mayor interacción y un vínculo de compromiso más fuerte. Resulta igualmente significativo que, si bien "El Diario de Pink Chick" es el blog con mayor cantidad de publicaciones, también es el que presenta el nivel más bajo de interacción y donde se responde en menor cantidad.

En pocas palabras, un mayor número de publicaciones no asegura una mayor interacción. Del mismo modo, la respuesta de comentarios por parte de las bloggers es esencial para que las lectoras se animen a participar de la conversación.

En relación a la frecuencia, las lectoras indicaron preferir que no se publique todos los días en el blog (esto implica compartir dicho post todos los días en Facebook) y, justamente, el blog con más publicaciones (“El Diario de Pink Chick”) fue el blog con menor interacción. Por lo tanto, se puede concluir que es mejor la calidad y relevancia de cada post, frente la cantidad de publicaciones realizadas.

Con respecto a los comentarios, se presenta un mayor número en Facebook que en el blog, lo que nos indica más interacción en esta red. Por otra parte, las redes sociales se constituyen como el principal nexo entre las lectoras y el blog y, por lo tanto, contribuyen a generar mayor tráfico.

\subsection{Relación con las marcas}

La relación de las bloggers con las marcas es un aspecto trascendental para comprender la importancia de los blogs en la industria de la moda.

En el caso de una colaboración, los contenidos se desarrollan a través de un trabajo en conjunto entre marcas y bloggers. Esto coincide con lo mencionado por los 
autores de la investigación "Organic and amplified eWOM in consumer fashion blogs": "los temas impulsados por las marcas en los blogs son presentados como si fueran orgánicos $\mathrm{y}$, muchas veces, los seguidores piensan que no existe una relación comercial entre ambas partes" (Kulmala, Mesiranta, \& Tuominen, 2013).

Conforme a los beneficios que trae para las marcas trabajar con bloggers, se mencionó el alcance, la credibilidad y la cercanía. Las marcas aprecian mucho estos tres beneficios gracias a que logran llegar a su público de una manera menos intrusiva, a través de un intermediario en el cual el público confía.

Entre los principales criterios de selección de un blog para una colaboración se encuentran la audiencia, el número de seguidores, el engagement con el que cuentan las bloggers, el posicionamiento, con qué marcas se relacionan y el background de cada una de ellas. Es importante recalcar que el número de seguidores va de la mano con el tipo de audiencia que tiene la blogger. Sin embargo, el hecho de que cuente con un gran número de seguidores no significa, necesariamente, que vaya con el posicionamiento de la marca. Si bien el alcance es un punto importante para la elección de la blogger, el punto más fuerte es el posicionamiento, que tiene que ser coherente con el de la empresa.

Por último, todas las expertas afirmaron que las bloggers tienen una influencia en las ventas y el comportamiento del consumidor, cuando se trata de acciones tácticas. Esto coincide con lo mencionado en la introducción por los autores López y Sicilia (2013) sobre la influencia del $e W O M$ en el comportamiento del consumidor y en las ventas. 


\section{CONCLUSIONES}

La presente investigación reafirma la importancia de las fashion bloggers dentro de la industria de la moda en Perú, tanto para las lectoras como para las marcas. Por un lado, las lectoras encuentran en las bloggers una fuente de información y de inspiración. Por otro, las marcas ven en las fashion bloggers una manera distinta y económica de conectar con su público objetivo. Hoy en día, desde start-ups hasta grandes casas de moda trabajan con bloggers para fomentar sus estrategias de marketing. A manera de conclusión, se presentan seis recomendaciones para las fashion bloggers basadas en los distintos puntos tocados a lo largo de la investigación.

- Calidad fotográfica: las fotografías pasan a ser piezas fundamentales para el "enganche" de las lectoras hacia los blogs. Se constituyen como elementos principales en los cuales se aprecia la razón de ser de los fashion blogs: looks, ropa, marcas y productos.

- Diseño limpio: un buen diseño no es condicional para que las lectoras prefieran un fashion blog sobre otro, pero un mal diseño genera rechazo. Es la carta de presentación de la blogger. No solo demuestra su interés y profesionalismo, también permite al usuario navegar con facilidad.

- Enlace con las redes sociales: es esencial que los posts sean compartidos en las redes sociales. Estas plataformas se vuelven en la principal fuente de conocimiento sobre últimas publicaciones, además de ser importantes para la interacción entre lectoras y bloggers.

- Las bloggers deben cuidar la credibilidad con la que cuentan: para las lectoras es importante sentir que las bloggers son sinceras en cuanto a sus recomendaciones. Sí, hacen publicidad, pero es fundamental que crean en las marcas que publicitan.

- Las bloggers deben tomar en cuenta la importancia de responder comentarios: esto genera un mayor nivel de interacción y contribuye a mantener el vínculo con las lectoras.

- Calidad antes que cantidad: en la investigación ha quedado demostrado que no 
siempre una mayor cantidad de posts significa una mayor interacción. Las lectoras prefieren contenidos más relevantes y mejor elaborados. 


\section{RECOMENDACIÓN}

Esta sección tiene como objetivo abordar una recomendación para futuras investigaciones que estén interesadas en tratar el tema de los fashion blogs y la moda en Perú:

- Instagram se constituye como la red social predilecta en la industria de la moda. En ella, distintos usuarios comparten sus gustos y preferencias en cuanto a marcas, diseñadores o tendencias. Si bien la creación de blogs tuvo un auge en Perú alrededor de 2013, hoy en día las bloggers se concentran más en generar contenido para Instagram y menos para su blog. Por ello, se recomienda para futuras investigaciones indagar sobre los beneficios de esta red social y sobre el posible futuro de los fashion blogs. 


\section{REFERENCIAS}

Aco Sánchez, C. (2014). "Los blogs de moda como recurso publicitario para las marcas de moda peruanas"(tesis de licenciatura). Pontificia Universidad Católica del Perú, Lima.

Ávila, Clara. (2014). El Blog de Clara Ávila. Recuperado de http://www.claraavilac.com/2014/11/03/como-medir-el-engagement-en-facebook/

Ballantine, P. W., \& Martin. (2005). Forming parasocial interaction in online communities. The University of Auckland, Auckland.

Blogueros en Boga. (2013). Ellos y Ellas: Caretas. Recuperado de http://ellosyellas.com.pe/reportajes/personajes-de-portada/blogueros-en-boga-baec

Chu, S.-C., \& Kamal , S. (2008). The effect of perceived blogger credibility and argument quality on message elaboration and brand attitudes: an exploratory study. University of Texas, Texas.

Colliander, J., \& Dahlén, M. (2011). Following the Fashionable Friend: The Power of Social Media - Weighing the Publicity Effectiveness Of Blogs versus Online Magazines. Estocolmo.

Horton, D., \& Wohl, R. (1956). Mass Communication and Para-Social Interaction: Observations on Intimacy at a Distance.

Kauppinen, P., \& Pavlova, A. (Mayo 2017). YouTube influence on Well-being brands: Understanding millennial perceptions of brand endorsements on fitness and health vlogs. Lund University - School of Economics and Management, Lund.

Kulmala, M., Mesiranta , N., \& Tuominen, P. (2013). Organic and amplified eWOM in consumer fashion blogs. School of Management, University of Tampere, Finland.

López, M., \& Sicilia, M. (2013). Boca a Boca Tradicional vs. Electrónico. La participación como factor explicativo de la influencia del boca a boca electrónico. Universidad de Murcia, Murcia.

López, M., \& Sicilia, M. (2014). eWOM as source of influence: The impact of participation in eWOM and perceived source trustworthiness on decision making. Murcia, Coquimbo.

Más Del Rey , E. (2015). El patrocinio de las marcas a los eglobloggers. Universidad Politcnica de Valencia, Valencia.

Miller, Z. (2010). The fashion blogosphere - a new era of publicity. Euromonitor International.

Moore, G. (2013). Promoción de Moda. Barcelona: Editorial Gustavo Gili. 
Moore, J. (2013). Ernest Ditcher on Word of Mouth Marketing. Recuperado de Brand Autopsy: http://www.brandautopsy.com/2013/09/ernest-dichter-on-word-of-mouthmarketing.html

Moreno Espinoza, C. (5 de Julio de 2017). Historia de influenciadores: Costo y beneficios en campañas publicitarias en internet. Diario Gestión, p32.

Peña, M. (2016). Uso de influencers en estrategias de marketing de moda en el Perú. Caso: Saga Falabella. Universidad de Lima, Lima.

Pérez Curiel, C., \& Clavijo Ferreira, L. (2017). Comunicación y social media en las empresas de moda: Asos como caso de estudio. Prisma Social N ${ }^{\circ} 18$ : Ciudadanía digital y open data access, Sevilla. 227-258.

Puro Marketing. (2014). 6 Métricas esenciales para gestionar la presencia de tu marca en Facebook. Recuperado de http://www.puromarketing.com/42/16508/metricasesenciales-para-gestionar-presencia-marca-facebook.html

Sedeke, K. (2012). Effective Fashion Blogs and Their Impact on the Current Fashion Industry.

The Influence of Fashion Blogs on Consumers. (2012). Recuperado de https://marketing.conferenceservices.net/resources/327/2958/pdf/AM2012_0224_paper.pdf

Valenzuela, S. (2013). El diario de Pink Chick: lectores, "influenciadores”, consumidores y oportunidades para las empresas. Universidad de Lima, Lima. 


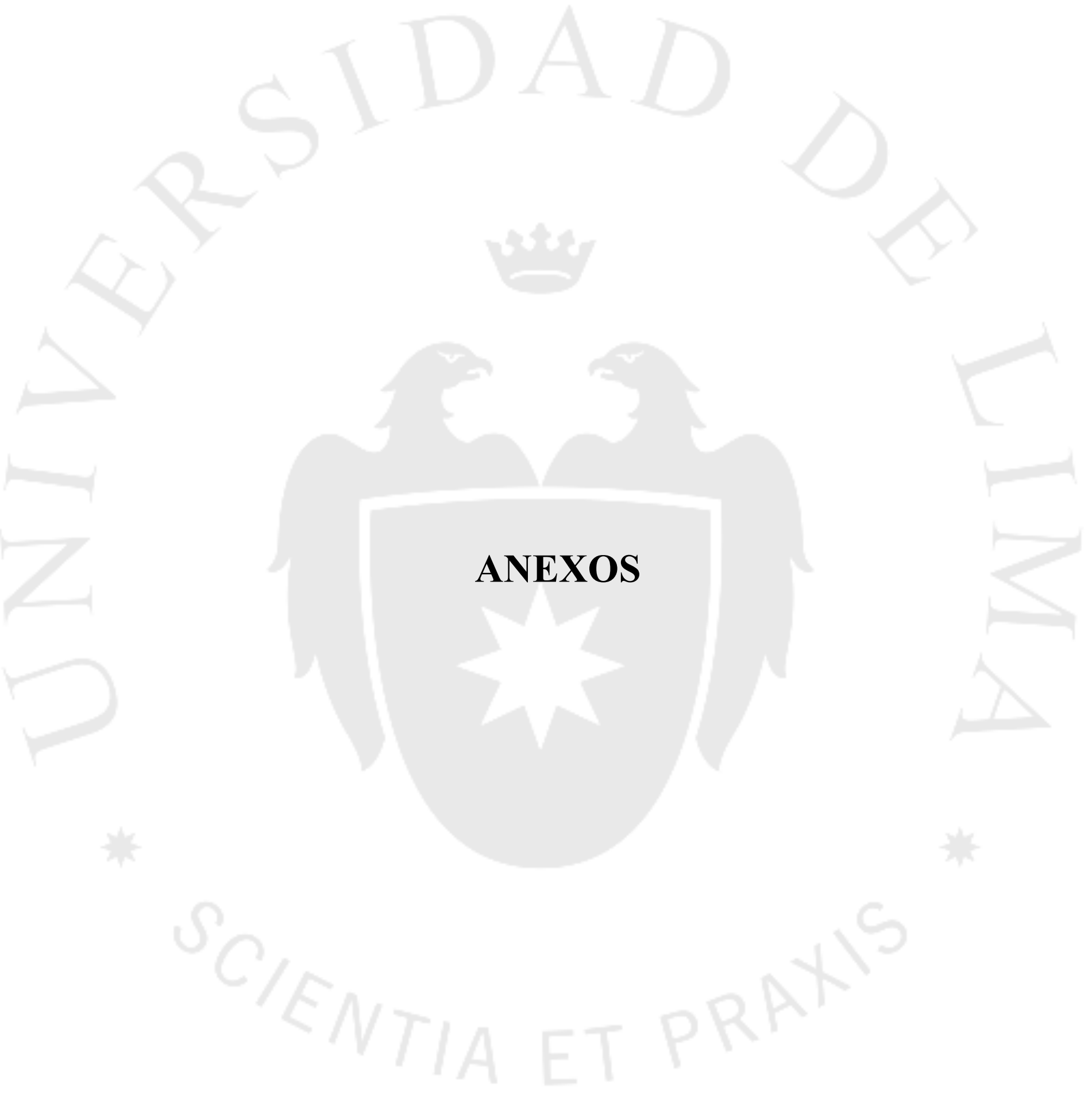




\section{Anexo 1: Análisis de contenido}

Fecha de análisis de contenido: semana del 11 de mayo al 17 de mayo de 2015.

\section{Guía de análisis de contenido descriptivo:}

Tabla de presentación de cada blog

\begin{tabular}{|l|l|}
\hline \multicolumn{2}{|c|}{ Nombre del blog } \\
\hline Autor & - \\
\hline Fecha de creación & - \\
\hline Número de fans en Facebook & - \\
\hline Publicidad / marcas & - \\
\hline Datos interesantes & - \\
\hline
\end{tabular}

Tabla para el análisis de cada post

\begin{tabular}{|l|l|}
\hline \multicolumn{2}{|l|}{ Nombre del post } \\
\hline Fecha & - \\
\hline Tema & - \\
\hline Descripción & - \\
\hline Fotografías & - \\
\hline Estilo de redacción & - \\
\hline Mención de marcas & - \\
\hline Links + Página de destino & - \\
\hline Número de likes en Facebook & - \\
\hline Número de shares en Facebook & - \\
\hline \multirow{5}{*}{ Comentarios en Facebook } & Positivos: - \\
\cline { 2 - 3 } & Negativos: - \\
\cline { 2 - 3 } & Total de comentarios: - \\
\cline { 2 - 3 } & ¿El blogger responde? - \\
\hline \multirow{2}{*}{ Link del post } & Positivos: - \\
\cline { 2 - 3 } & Negativos: - \\
\cline { 2 - 3 } & Total de comentarios: - \\
\cline { 2 - 2 } & ¿Elogger responde? - \\
\hline \multirow{2}{*}{ Com el blog } & - \\
\hline
\end{tabular}




\section{Diseño:}

Tabla para el análisis del diseño:

\begin{tabular}{|l|l|l|l|l|}
\hline \multicolumn{3}{|c|}{ Diseño del blog } \\
\hline Nombre del blog & $\begin{array}{l}\text { Soporte del } \\
\text { sitio web }\end{array}$ & Tipografía & Colores & Diagramación \\
\hline Blog 1 & & & & \\
\hline Blog 2 & & & & \\
\hline Blog 3 & & & & \\
\hline
\end{tabular}

\section{Contenido:}

Tabla para las principales secciones que conforman los blogs

\begin{tabular}{|l|l|}
\hline \multicolumn{1}{|c|}{ Sección } & \multicolumn{1}{c|}{ Descripción } \\
\hline Sección 1 & \\
\hline Sección 2 & \\
\hline Sección 3 & \\
\hline
\end{tabular}

Tabla para analizar los temas principales tocados en los posts.

\begin{tabular}{|l|l|l|l|}
\hline \multicolumn{1}{|c|}{ Blog } & \multicolumn{1}{|c|}{ Título del post } & Tema del post & \multicolumn{1}{c|}{$\begin{array}{c}\text { Referencia a vida } \\
\text { personal }\end{array}$} \\
\hline \multirow{3}{*}{ Blog 1} & - & - & - \\
\hline \multirow{3}{*}{ Blog 2} & - & - & - \\
\cline { 2 - 5 } & - & - & - \\
\hline \multirow{3}{*}{ Blog 3} & - & - & - \\
\cline { 2 - 5 } & - & - & - \\
\cline { 2 - 5 } & - & - & - \\
\hline & - & - & - \\
\cline { 2 - 4 } & - & - & - \\
\cline { 2 - 4 } & - & - & - \\
\hline
\end{tabular}




\section{Otras variables:}

Tabla para determinar la frecuencia de publicaciones en el blog

\begin{tabular}{|l|l|l|}
\hline \multicolumn{1}{|c|}{ Blog } & \multicolumn{1}{|c|}{$\begin{array}{c}\text { Núm. de publicaciones } \\
\text { semanales }\end{array}$} & Frecuencia \\
\hline $\mathrm{B} \log 1$ & - & - \\
\hline $\mathrm{B} \log 2$ & - & - \\
\hline $\mathrm{B} \log 3$ & - & - \\
\hline
\end{tabular}

Tabla para el análisis de la publicidad

\begin{tabular}{|l|l|l|}
\hline \multicolumn{2}{|c|}{ Banners publicitarios } \\
\hline Nombre del blog & Marca & Landpage \\
\hline Blog 1 & & \\
\hline Blog 2 & & \\
\hline Blog 3 & & \\
\hline
\end{tabular}

\section{Engagement:}

Tabla para determinar el engagement en Facebook

\begin{tabular}{|l|l|l|l|}
\hline \multicolumn{1}{|c|}{ Blog } & Núm. fans & Núm. likes/comments/shares & Engagement \\
\hline Blog 1 & - & - & - \\
\hline Blog 2 & - & - & - \\
\hline Blog 3 & - & - & - \\
\hline
\end{tabular}




\section{Anexo 2: Focus Group lectoras}

\section{Guía de los focus group}

\section{Presentación}

Hola, gracias a todas por venir. Como les conté en un principio, este es un focus sobre fashion blogs en el Perú para la tesis que estoy haciendo. Es importante decirles que no hay respuestas correctas ni incorrectas. Así que siéntanse libres de expresar sus distintos puntos de vista cuando lo crean conveniente. Además, no tienen que pedirme permiso para hablar, pueden hacerlo cuando deseen. Lo importante es que podamos expresar todas nuestras ideas.

\section{Blogs de moda que visitan y razones por las cuáles leen esos blogs}

- Me gustaría comenzar conociendo qué es un fashion blog para ustedes.

- ¿Cuál creen que es el propósito de un fashion blog?

- ¿Qué blogs peruanos conocen?

- ¿Cuáles son sus blogs favoritos o los blogs que más leen? ¿Por qué son sus favoritos?

\section{Contenidos}

- ¿Cada cuánto los visitan?

- En cuanto a los blogs que han visto en Perú, ¿Recuerdan cuales son los temas más comunes que suelen tratar las bloggers?

- ¿Qué tipo de posts o temas del blog les gustan más? ¿Los que enseñan el outfit del día, los que dan información sobre tendencias, sobre colecciones o los que cuentan experiencias con productos? 


\section{Contenido visual}

- ¿Qué opinan de las fotografías de los blogs?

- ¿Les parece importante que sean de buena calidad? (En cuanto a la composición, tamaño, la post edición).

- ¿Creen que las fotografías son uno de los elementos más importantes del blog?

- ¿Dirían que la buena calidad de las imágenes y de las fotografías son aspectos que influyen en que ustedes lean o no un respectivo blog?

- Ahora último de hecho han notado que las bloggers peruanas han comenzado a postear videos que tocan distintos temas. ¿Han visto alguno? ¿Qué les parecen? ¿Les gustan? ¿No les gustan? ¿Por qué?

- ¿Cuáles creen que son las ventajas de los videos frente a los posts?

\section{Diseño}

- ¿Recuerdan más o menos como son los diseños de los blogs que leen?

- ¿Cómo les gusta que sean? Por ejemplo, minimalistas, sencillos y fáciles de comprender, muy visuales (con bastantes fotos).

- ¿Las fotografías es un factor que influye en sus percepciones con respecto a los fashion blogs?

\section{Vínculos}

- Deben haber notado que los blogs suelen tener al final de cada post las marcas de ropa que se están mostrando. Y muchas veces estas marcas se encuentran vinculadas a la web de la empresa o a su perfil en Facebook, ¿Qué opinan de esto? ¿Les parece importante que se especifique de dónde es cada producto?

\section{Bloggers}

- ¿Cómo describirían a las bloggers?

- ¿Cómo dirían que es la forma en que se expresan en sus posts? Por ejemplo, amigable, cercana, distante, fría, con un lenguaje sencillo, simple, complicado. 
- Deben haber notado que las bloggers revelan distintos aspectos de su vida privada en sus respectivos blogs y redes sociales ¿Les parece importante conocer parte de la vida privada de las bloggers? Por ejemplo, quiénes son, que hacen, en donde trabajan, qué estudian, que les gusta hacer, a donde viajan. Si o no ¿Por qué?

- ¿Creen que el hecho de que toquen temas personales hace que se vuelvan más atractivos y que se genere una relación más fuerte con sus lectoras?

- ¿Creen que características como la personalidad que transmite la blogger influye en que les guste más un blog?

\section{Confianza}

- ¿Confían en las recomendaciones que les dan las fashion bloggers? ¿Por qué?

\section{Enlace con las redes sociales}

- ¿Por medio de que redes sociales siguen a las bloggers?

- ¿A través de qué red social se enteran más de las publicaciones de las bloggers?

- ¿Les parece importante que las bloggers tengan una fuerte presencia en las redes sociales? ¿Por qué?

\section{Interacción}

- ¿Alguna vez han hecho un comentario en algún blog? O ¿En alguna red social del blog?

- ¿La blogger les contestó? ¿Qué le preguntaron? ¿Qué suelen preguntar?

- ¿Qué tan importante les parece que la blogger responda los comentarios?

- ¿Por qué medio creen que las bloggers interactúan más con las lectoras?

\section{Frecuencia de las publicaciones}

- ¿Cada cuanto tiempo creen que es apropiado que las bloggers publiquen un nuevo post?

- ¿Les parece importante que realicen publicaciones frecuentes? 


\section{Marcas y publicidad}

- ¿Han notado publicidad en los blogs? ¿Qué opinan de ella?

- ¿Cómo las hace sentir esta publicidad? ¿Les molesta o incomoda?

- ¿Cuáles creen que son las intenciones de la blogger al momento de dar recomendaciones sobre distintos productos?

- ¿Les parece importante que la publicidad o las marcas vayan con el estilo personal de la blogger?

- ¿Les gusta que las bloggers mencionen distintas marcas? O ¿Les molesta?

\section{Conclusión}

- Tomando en cuenta todos los elementos de los que hemos hablado, Si tuvieran que darme tres razones por la cuáles prefieren un fashion blog ¿cuáles serían?

- ¿Por qué creen que las fashion bloggers se han vuelto tan conocidos en los últimos años?

Muchas gracias a todas por haber participado en este focus group. Sin duda nos han ayudado a recopilar información valiosa y de gran utilidad para esta investigación. 


\section{Anexo 3: Entrevistas a expertas de marketing}

\section{Nombres y funciones de las expertas de marketing entrevistadas:}

- Eliana Obregón - Jefa de producto Larcomar.

- Alejandra Aldave - Jefa de producto InOutlet Premium Lurín e InOutlet Faucett.

- Andrea Cruz - Coordinadora de Marketing Mac Cosmetics.

- Valeria Ugaz - Coordinadora de Marketing L'Oréal Professionnel.

- Evelyn Uribe - Coordinadora de Marketing C.C. La Rambla.

\section{Guía entrevista}

Presentación

Buenos días.

Antes de comenzar quisiera agradecerle por su tiempo y contarle el motivo de esta entrevista. Soy ex alumna de la Universidad de Lima de la carrera de Comunicación y, actualmente, estoy haciendo una investigación sobre los fashion blogs para poder titularme. Por ello, sería ideal poder grabar esta entrevista, quisiera saber si está de acuerdo.

\section{Introducción}

- Para empezar, quisiera que me cuente un poco sobre su actual trabajo en marketing y sus funciones.

\section{Estrategia 2.0}

- ¿Podría decirme cómo está estructurada su estrategia digital?

- En cuanto a redes sociales, sitio web, influencers $u$ otros. 
- ¿Cuál diría que es la principal ventaja de estos medios para (nombre de empresa)?

- ¿Me podría contar la forma en la que (nombre de empresa) busca conectar con su público a través de estos medios? ¿Qué ejemplos podría darme?

\section{Colaboraciones anteriores con las bloggers}

- ¿Han trabajado anteriormente con fashion bloggers? ¿Podría darme un caso en particular?

- ¿Para qué ocasión se realizó esta colaboración? Por ejemplo, para el lanzamiento de un producto, para utilizar a una blogger como imagen de marca, para hacer branding, para una campaña publicitaria o para una promoción.

- ¿Cuáles fueron los objetivos de esta colaboración?

- ¿Podría contarme en base a qué criterios se eligió a la blogger con la que trabajaron?

- ¿Podría decirme cuáles fueron los resultados obtenidos de esta colaboración?

\section{Frecuencia de colaboraciones con bloggers}

- ¿Con qué frecuencia realizan estas colaboraciones? ¿Se hacen regularmente?

- ¿Podría decirme cada cuánto tiempo aproximadamente?

\section{Contenidos}

- Quisiera que me cuente cómo se organizan con las bloggers para generar contenido. ¿Son ustedes quienes establecen qué tipos de contenidos deben generarse y dónde deben publicarse?

- ¿Qué tipos de contenidos se generan junto a las bloggers? Por ejemplo, posts contratados en redes sociales, concursos, reviews de productos, videos en colaboración, banners en el blog.

- En el caso de (nombre de marca), ¿cuál de estos tipos de contenidos se usan más? ¿Podría contarme cuáles son las formas para producir estos contenidos?

- ¿Cuál diría que es el tipo de contenido que atrae más al publico? ¿Por qué? 
- ¿En qué redes sociales o plataformas publican estos contenidos?

- ¿Cuál diría que es la red social en la que este tipo de colaboraciones funciona mejor?

\section{Circunstancias}

- ¿Podría contarme en qué circunstancias es que deciden que desean o necesitan trabajar con bloggers?

- ¿Estas colaboraciones responden a una necesidad en particular?

- Usualmente, ¿tienen motivos específicos para llevar a cabo estas colaboraciones o es algo que se decide espontáneamente?

- ¿Podría decirme quién es el encargado de tomar esta decisión?

\section{Beneficios de las colaboraciones con las bloggers}

De forma general, ¿cuáles son los principales beneficios de trabajar con bloggers?

- ¿En el caso de lanzamientos de productos, cuáles son los principales beneficios que aporta una colaboración?

- ¿Cuáles son los principales beneficios del uso de una blogger como imagen de marca?

- He notado que muchas marcas suelen invitar a bloggers a distintos eventos, ¿sucede esto en el caso de (nombre de la marca)?

- ¿Qué beneficios trae invitar a bloggers a eventos?

- En el caso de (nombre de marca), ¿para qué tipo de acción de marketing es más beneficioso trabajar con bloggers? ¿Me podría dar un ejemplo?

- ¿Cómo ha sido la respuesta del público de (nombre de marca) ante el uso de bloggers? ¿Positivo o negativo? ¿Por qué?

\section{Criterios de selección de las bloggers}

- ¿Podría mencionar cuáles son los criterios de selección de una blogger para realizar una colaboración con ella?.

- ¿Podría contarme acerca de un caso en particular? 
- De manera general, ¿cuáles son los principales criterios que se toman en cuenta para trabajar con una blogger? Por ejemplo, el posicionamiento, la profesionalidad y reputación de la blogger, su estilo, el público objetivo, el número de seguidores, la afinidad de la blogger con la marca.

- ¿Cuál o cuáles de los criterios anteriormente mencionados diría que es el más importante para (nombre de marca)?

\section{Tipos de industria por blogger}

- ¿Para qué tipo de productos o en qué industria considera que es mejor trabajar en conjunto con bloggers? Por ejemplo retail, belleza, moda.

- ¿En el caso de (nombre de marca) cuál es el principal objetivo de trabajar con bloggers?

\section{Influencia del uso de bloggers en ventas}

- ¿De acuerdo a sus experiencias anteriores, diría que las colaboraciones con bloggers tienen una influencia en las ventas?

- Si es así, ¿podría contarme sobre algún caso en el que hubo un impacto directo entre las ventas y el uso de bloggers?

- En el caso de (nombre de marca), ¿cree que las bloggers influyen en el comportamiento del consumidor?

- Si es así, ¿cómo influye? ¿Qué comportamientos genera en el consumidor?

- ¿Diría que, hoy en día, para (nombre de marca) es esencial trabajar en colaboración con bloggers?

- ¿Desde qué momento diría que es importante para (nombre de marca) trabajar con bloggers? ¿En qué momento son contactados?

- Finalmente, ¿qué espera (nombre de marca) de estás colaboraciones?

Muchas gracias por haber respondido a las preguntas. Sin duda serán de gran utilidad para esta investigación. 